\title{
RANCANG BANGUN SISTEM KONTROL DAN SISTEM PROTEKSI MOTOR LISRIK TERHADAP PANAS (OVER HEATING) SERTA PERINGATAN DINI TERHADAP GANGGUAN TEGANGAN DAN ARUS BERBASIS ATMEGA 328
}

\author{
Moh. Sholeh", Affan Bachri', Arief Budi Laksono ${ }^{2}$ \\ ${ }^{1)}$ Program Studi Jurusan Teknik Elektro, Fakultas Teknik, Universitas Islam Lamongan \\ Dosen Jurusan Teknik Elektro, Fakultas Teknik, Universitas Islam Lamongan 2,3 \\ E-mail:Matshunagashohel39@gmail.com ${ }^{1}$, avanbe@gmail.com ${ }^{2}$, ariefbudila@gmail.com ${ }^{3}$
}

\begin{abstract}
Electric motor is the type of motor that is most often used in everyday life. This is because the electric motor has several advantages that are not owned by a DC motor, which is simple construction and the price is quite cheap. However, if the motor is used continuously can experience heat or over heat, which can cause the motor to be damaged or burned. To overcome these problems required a system that can secure the motor from the heat that caused by the motor is often in use. This tool uses LM35 temperature sensor and is able to keep the motor always at its optimum temperature. In this system is also installed voltage sensors and current sensors to read the value of voltage and the current required by the motor. The value of temperature, current and voltage are displayed on LCD $2 x 16$. In serial communication, initialization of baudrate on micro controller Atmega 328 is adjusted with baudrate computer, that is equal to $9600 \mathrm{bps}$. The system will provide a buzzer sound alert when the temperature reading is at $80.51^{\circ} \mathrm{C}$. Sensor LM35 function to read the temperature on the motor, when the motor is given a voltage source $220 \mathrm{~V}$. At the time of the motor with a temperature of $31.74^{\circ} \mathrm{C}$ up to $75.20^{\circ} \mathrm{C}$ motor in a safe state, but at temperatures above $80.51^{\circ} \mathrm{C}$ motor in the state of overheating then there is a response from the micro controller to activate the relay so that the relay will break the voltage that flows on the motor and cause the motor to stop automatically, and buzzer gives a warning that the motor overheating. If this warning is allowed it can cause the motor to burn and will cause much greater repair costs.
\end{abstract}

Keywords: Atmega 328, Current Sensor, LM35 Sensor, Voltage Sensor, Relay.

\section{PENDAHULUAN}

Dalam skala besar, proses pemindahan air tidak mungkin dilakukan secara manual oleh manusia, perlu adanya sistem kontrol untuk proses tersebut. Peran serta teknologi dalam otomasi industri tidak hanya sebagai alat bantu manusia untuk melakukan proses produksi, melainkan dapat memperingan kerja manusia dengan kualitas hasil produksi yang efisien.Motor listrik merupakan perangkat elektromagnetis yang menghasilkan energi mekanik. Energi mekanik digunakan untuk memutar impeller pompa dan lain-lain. Dengan tidak adanya gangguan selama proses produksi maka hasil yang diperoleh akan menghasilkan produk yang berkualitas baik.Gangguan pada pompa air dengan motor induksi tiga phasa ini mempunyai dampak yang sangat berbahaya bila dibiarkan secara terus menerus.

\section{METODE PENELITIAN \\ Perancangan hard ware}

Dalam penelitian ini metode yang digunakan meliputi perancangan rangkaian power suplai, perancangan sensor arus, sensor tegangan dan sensor suhu agar diperoleh data dan informasi yang akurat yang nantinya di tampilkan di LCD. Serta perancangan relay pada motor dapat bekerja dengan semestinya.

\section{Perancangan soft ware}

Perancangan soft ware dalam penelitian ini meliputi :

Koding sensor Arus ACS 71230 A

Koding sensor Tegangan ZMPT101B

Koding sensor LM 35

Koding keseluruhan 


\section{Flow Chart sistem kerja alat}

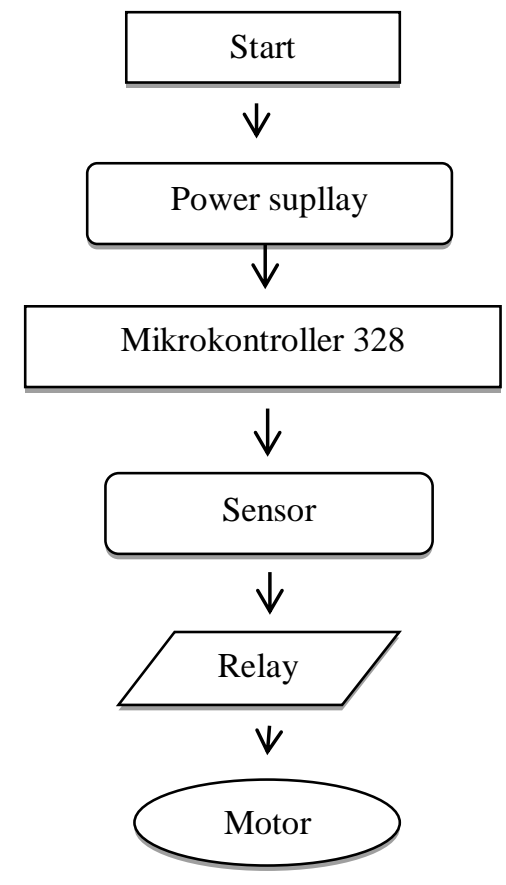

Gambar 1. Flow Chart sistem kerja alat

\section{Teknik Analisa Data}

Karena dalam penelitian ini membuat alat sistem kontol dan proteksi motor terhadap panas ( over heat) serta peringatan dini terhadap gangguan tegangan dan arus berbasis mikrokontroller ATMega328 maka analisa yang dilakukan adalah dengan mengimplementasikan alat tersebut dalam motor industri.

\section{Metode Pengujian}

1. Rangkaian Power Supplay

2. Rangkaian Mikrokontroller

3. Rangkaian sensor ACS 71230 A

4. Rangkaian sensor Suhu LM 35

5. Rangkaian sensor Tegangan ZMPT101B

6. Rangkaian Relay dengan Motor

7. Rangkaian Prototype keseluruhan

\section{HASIL DAN PEMBAHASAN}

Dalam merancang sistem kontrol dan proteksi motor listrik di perlukan adanya suatu rangkaian yang terpadu untuk bisa digunakan dan berfungi dengan baik, baik itu perancangan Hardware maupun Softwarenya . Untuk itu di perlukan adanya rangkaian yang mendukung selama proses pengerjaan dan pengujian.

\section{A. Pengujian Sensor Arus ACS 712}

Pada pengujian rangkaian sensor arus ACS712-30A dilakukan dengan cara yang sederhana yaitu memberikan tegangan dari PLN 220 V. Rangkaian ini nantinya akan membaca arus yang di pakai oleh motor listrik apakah arus yang di butuhkan oleh motor listrik tersebut sesuai dengan kapasitsanya. Berikut rangakaian sensor arus dalam motor listrik:

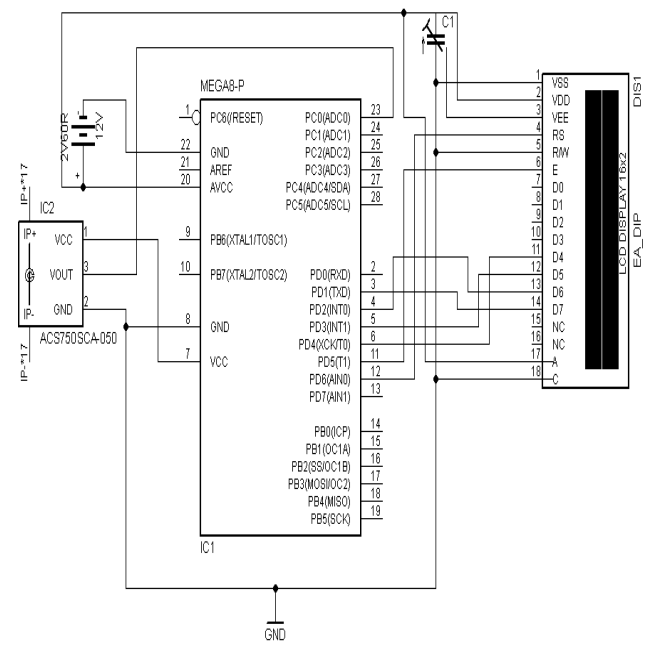

Gambar 2. Rangkaian skematik sensor arus ACS 712

Dari pengujian menggunakan motor listrik, terlihat hasil yang didapat setelah pengujian adalah sebesar 0,31 A dengan tegangan 220 V.

Berikut tabel pengukuran arus menggunakan beban motor :

Tabel 1. Pengukuran sensor ACS 712 30A

\begin{tabular}{cc} 
Volt AC & Arus \\
\hline 0 & 0,01 \\
\hline 220 & 0,06 \\
\hline 220 & 0,09 \\
\hline 220 & 0,16 \\
\hline 220 & 0,23 \\
\hline 220 & 0,25 \\
\hline 220 & 0,31
\end{tabular}

Berdasarkan pengujian di atas disimpulkan bahwa sensor arus dapat berfungsi dengan baik, dengan tegangan input $220 \mathrm{~V}$ dengan arus $0,25 \mathrm{~A}$. 


\section{B. Pengujian Sensor Tegangan ZMPT101B}

Sama halnya dengan sensor arus, sensor ini membaca tegangan yang di butuhkan oleh motor listrik apakah tengangan motor yang di gunakan sesuai dengan tegangan yang tertera pada badan motor listrik tersebut. Berikut rangkaian sensor tegangannya:

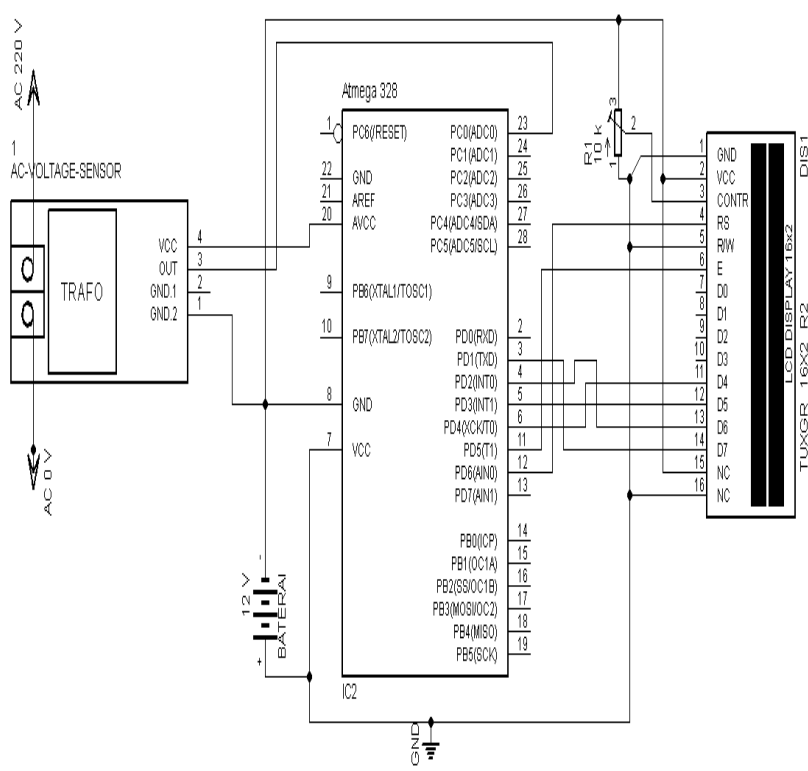

Gambar 3. Rangkaian skemaik sensor tegangan ZMPT101B

Dari pengukuran di atas terdapat selisih nilai yang di dapatkan dari pengukuran melalui tampilan lcd dan mulitimeter digital. Hal ini di karenakan sinus pada tegangan tidakalah konstan sehinggan nilai yang keluar dari pembacaan sensor tegangan selalu berubah ubah.

Berikut tabel pengukuran tegangan dengan beban motor listrik :

Tabel 2. Pengukuran sensor tegangan ZMPT101B

\begin{tabular}{cc}
$\begin{array}{c}\text { Input Volt } \\
\mathrm{AC}\end{array}$ & Volt dalam beban motor \\
\hline 220 & 219 \\
\hline 220 & 220 \\
\hline 220 & 221 \\
\hline 220 & 220 \\
\hline 220 & 223
\end{tabular}

Berdasarkan pengujian di atas dapat di simpulkan bahwa tegangan dengan beban motor listrik selalu berubah - ubah dan sensor tersebut dapat berfungsi dengan baik serta sesuai dengan kapasitas tegangan yang dibutuhkan oleh motor tersebut, adalah sama $220 \mathrm{~V}$ dalam beban motor dengan input tegangan $220 \mathrm{~V}$.

\section{Pengujian sistem Atmega 328}

Rangkaian ini merupakan bagian utama dari sebuah mikrokontroller. Jika tidak ada rangkaian ini maka sebuah mikrokontroller tidak akan dapat bekerja sebagaimana mestiya. Berikut rangkaian mini sistem Atmega 328 :

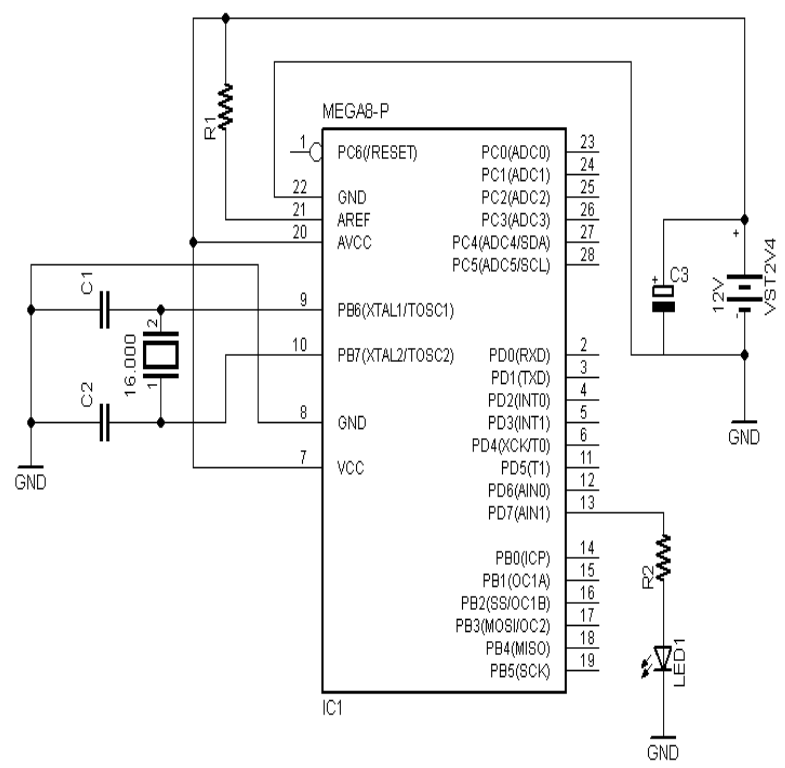

Gambar 4. Rangkaian skematik mini sistem Arduino

Pada gambar di atas mini sistem arduino di suplai dengan tegangan 12 volt kemudian distabilkan lagi dengan IC 7805. Mini sistem ini bekerja dengan tegangan 5 volt dengan program blink dan bekerja dengan baik.

\section{Pengujian power supply}

Rangkaian ini merupakan sumber daya yang mensuplai tegangan dari rangkaian utama mini sistem arduino, rangkaian ini mengunakan IC regulator 7812 dan 7805 . Berikut rangkaian power supplynya:

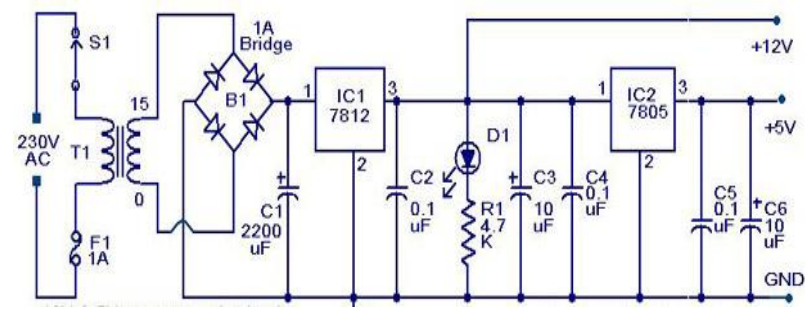

Gambar 5. Rangkaian skematik power supply 
Dari pengukuran di atas di peroleh data sebagai beikut:

Tabel 3. Hasil pengukuran power supply

\begin{tabular}{ccl} 
Input & Output & \multicolumn{1}{c}{ Keterangan } \\
\hline 7812 & 12,00 & Dari pengukuran \\
& & menggunakan Avo \\
& meter keluaran tegangan \\
& dari IC 7812 adalah \\
& & 12,00 volt , tanpa beban \\
\hline 7805 & 4,98 & Dari pengukuran \\
& & menggunakan Avo \\
& & meter keluaran tegangan \\
& dari IC 7805 adalah 4,98 \\
& volt, tanpa beban
\end{tabular}

Berdasarkan pengujian di atas dapat di simpulkan bahwa kedua IC Regulator tersebut berfungsi dengan baik dan tegangan yang di butuhkan oleh mikrokontroller adalah 5 Vdc.

\section{E. Pengujian Sensor Suhu LM 35}

Rangkaian ini membaca suhu yang ada didalam motor menggunakan sensor Lm 35, kemudian output dari sensor ini ditampilkan dalam tampilan LCD ukuran $16 \times 2$. Berikut tampilan pembacaan sensor dalam LCD :

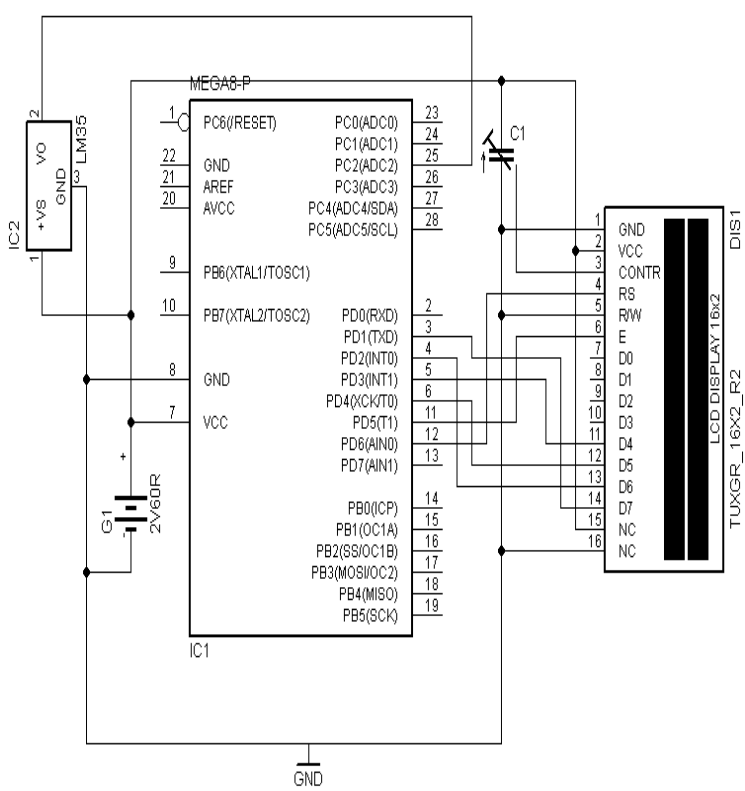

Gambar 6. Rangkaian skematik LM 35 Arduino dengan LCD

Dari pengujian rangkaian ini mikrokontroller disuplai dengan input $12 \mathrm{Vdc}$ dan diturunkan dengan IC regulator 7805 yang ada pada mini sistem. Kemudian dilakukan dengan mengukur temperatur suhu ruang dengan menggunakan LM 35 dan sensor ini disuplai dengan tegangan input $5 \quad \mathrm{Vdc}$ dari mikrokontroller begitu pula dengan tegangan input pada LCD.

Berikut tabel pengukuran sensor LM 35 dengan beban motor dapat dilihat pada tabel 4. di bawah ini :

Tabel 4. Hasil pengukuran sensor LM 35

\section{Hasil pembacaan Suhu Motor}

Sensor

\begin{tabular}{cc}
\hline $30,27^{\circ} \mathrm{C}$ & Suhu ruangan \\
\hline $31,74^{\circ} \mathrm{C} \mathrm{s} / \mathrm{d} 41,56^{\circ} \mathrm{C}$ & Belum panas \\
\hline $42,48^{\circ} \mathrm{C} \mathrm{s} / \mathrm{d} 45,90^{\circ} \mathrm{C}$ & Mulai panas \\
\hline $46,88^{\circ} \mathrm{C} \mathrm{s} / \mathrm{d} 59,57^{\circ} \mathrm{C}$ & Sedang \\
\hline $62,50{ }^{\circ} \mathrm{C} \mathrm{s} / \mathrm{d} 72,75^{\circ} \mathrm{C}$ & Agak panas \\
\hline $75,20^{\circ} \mathrm{C} \mathrm{s} / \mathrm{d} 79,59^{\circ} \mathrm{C}$ & Terlalu panas \\
\hline $80,51^{\circ} \mathrm{C}$ & Over heat
\end{tabular}

Berdasarkan pengujian di atas dapat disimpulkan bahwa suhu motor yang melampaui batas ukur dengan suhu $80,51^{\circ} \mathrm{C}$, dapat mengakibatkan motor tersebut terbakar jika digunakan terus menerus, dan sensor suhu berfungsi dengan baik.

\section{F. Pengujian rangkaian Relay}

Pada perancangan ini menggunakan 1 buah relay HKE HRS4H-S-DC 5V tegangan rendah, 5VDC, sehingga dapat langsung dihubungkan pada sistem mikrokontroler. Tipe relay tersebut adalah SPDT (Single Pole Double Throw): 1 Common, 1 NC (Normally Close), dan 1 NO (Normally Open). Berikut tampilan rangkaian relay:

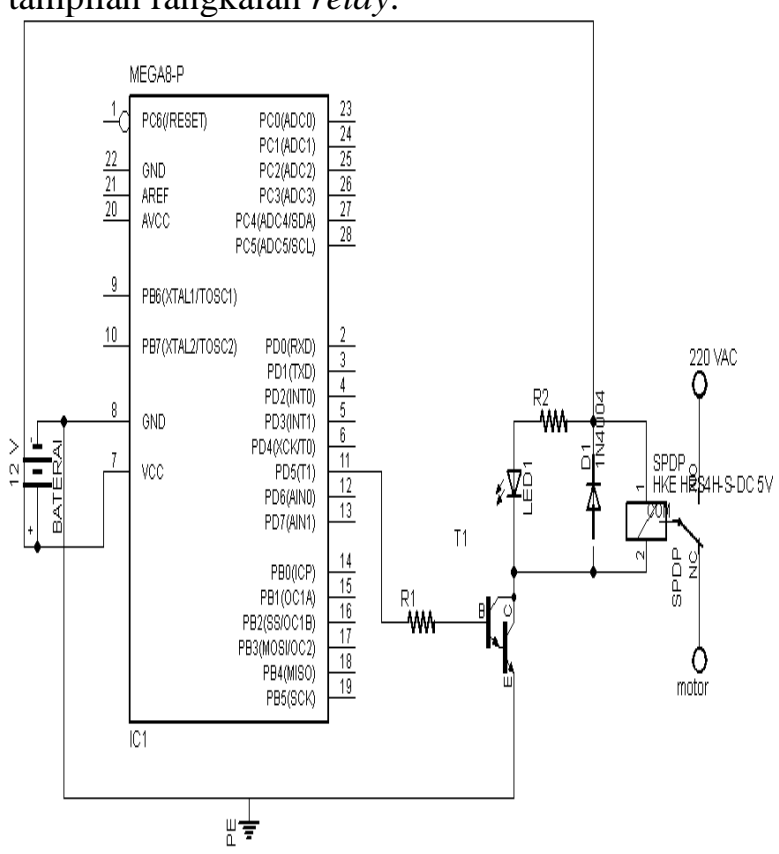

Gambar 7. Rangkaian skematik relay 
Rangkaian ini bekerja dengan menerima masukan intruksi dalam mikrokontroller apabila intruksi bernilai 1 ( high) maka relay akan bekerja dengan keadaan NC, sebaliknya jika intruksi bernilai 0 ( low ) maka relay dalam keadaan NO.

\section{G. Pengujian Keseluruhan}

Pengujian ini adalah pengujian secara langsung dimana semua bagian dihubungkan menjadi sebuah sistem yang diinginkan pada saat merancang alat ini. Pengujian ini di lakukan dengan sumber PLN dengan tegangan $220 \mathrm{~V}$. Tegangan input yang diberikan ada dua yaitu tegangan input $12 \mathrm{~V}$ untuk mikrokontroler ATmega 328 dan rangkaian relay serta tegangan input $5 \mathrm{~V}$ untuk rangkaian sensornya.

Berikut rangkaian prototype secara keseluruhan :

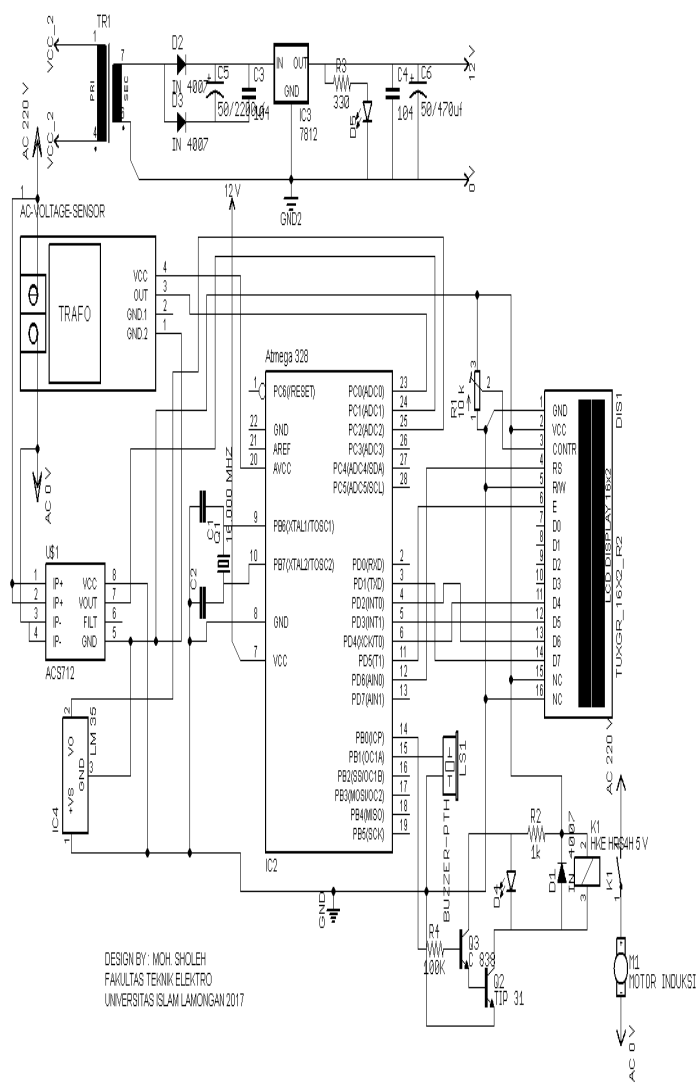

Gambar 8. Rangkaian skematik kontrol dan proteksi motor listrik

Pengujian dilakukan dengan cara mengaktifkan input AC $220 \mathrm{~V}$ menggunkan power suplay, begitu pula dengan mikrokontroller. Pada saat mikrokontroller dinyalakan secara otomatis led yang ada pada mikrokontroller hidup, itu berarti sistem telah siap dinyalakan dan dioperasikan dengan seksama. Saat sensor-sensor aktif dengan cara memberikan suatu masukan tegangan 5 VDC, sehingga terhubung arus ke setiap sensornya, dimana sensor tersebut akan berfungsi, yang nantinya hasil dari pembacaan ke dua sensor akan ditampilkan dalam LCD ukuran 16 x 2, begitu pula dengan sensor suhu yang mendeteksi adanya panas yang di akibatkan oleh motor listrik.

Tabel 5. Hasil pengujian keseluruhan :

\section{Jenis Keterangan \\ rangkaian}

Sensor Berfungi dengan baik, arus

ACS 712 yang terukur pada beban motor

$30 \mathrm{~A}$ sebesar $0,25 \mathrm{~A}$ dengan input tegangan 220 VAC. Akan tetapi pengujian sensor kurang efektif di karenakan sensitifitas pembacaan sensor yang lambat.

Sensor Berfungsi dengan baik, sesuai tegangan dengan yang di ukur melalui

ZMPT101 AVOmeter maupun sensor B tegangan ZMPT101B dengan hasil yang sama yaitu $220 \mathrm{~V}$ sesuai dengan tegangan motor yang di butuhkan.

Sensor Pembacaan nilai yang terukur LM 35 melalui panas pada motor di tampilkan melalui LCD ukuran $16 \times 2$ dan nilai yang terukur oleh sensor sesuai dengan nilai yang di tentukan dan sensor berfungsi dengan baik.

Power Output dari power suplay ini
supply memiliki 2 keluaran tegangan. Tegangan 12 VDC untuk rangkaian mensuplai rangkaian relay dan 5 VDC mensuplai rangakian mini sistem mkrokontroller. Keduanya berfungsi dengan baik sesuai dengan kapasitas yang di butuhkan.

Mikrokon Pin analog A0, A1, A2 troller menerima masukan dari tiap Atmega tiap sensor yang ada dalam 328 rangkaian sistem kontol ini. Dan ADC bekerja dengan baik. 
Relay

$$
\begin{aligned}
& \text { Rangkaian ini sebagai pemutus } \\
& \text { tegangan pada motor jika } \\
& \text { motor mengalami over heat, } \\
& \text { relay akan bekerja apabila ada } \\
& \text { tegangan yang masuk melaui } \\
& \text { kontak COM, NO dan NC. } \\
& \text { Jika indikator pada relay nyala, } \\
& \text { berarti relay tersebut berfungsi } \\
& \text { dengan baik. } \\
& \text { Sebagai tanda peringatan } \\
& \text { bahwa motor mengalami panas } \\
& \text { ( over heat ). Dan buzzer } \\
& \text { berfungsi dengan baik. }
\end{aligned}
$$

Buzzer Sebagai tanda peringatan

Dari semua pengujian rangkaian di atas dapat disimpulkan bahwa sistem kerja alat berfungsi sebagaimana mestinya. Pada suhu $31,74{ }^{\circ} \mathrm{C}$ sampai dengan $75,20{ }^{\circ} \mathrm{C}$ motor dalam keadaan aman, tetapi pada suhu di atas $80,51{ }^{\circ} \mathrm{C}$ motor dalam keadaan overheating dan motor mengalami panas yang melebihi ambang batas, jika motor melebihi dari suhu yang di tentukan maka bisa di ketahui bahwa motor tersebut dapat terbakar.

\section{PENUTUP}

\section{Kesimpulan}

Dari beberapa pengukuran di atas dari tugas akhir ini dapat di simpulkan sebagai berikut : Power suplay sebagai sumber untuk menjalankan semua sistem mikrokontroller. Sensor Arus, sensor Tegangan dan sensor suhu berfugsi dengan baik, keluaran dari setiap sensor harus sesuai dengan port yang digunakan, apabila terjadi kesalahan maka data ADC tidak dapat diterima oleh mikrokontroller Atmega 328 dan tidak dapat ditampilkan ke dalam LCD. Kemudian nilai yang terukur pada tiap - tiap sensor dapat dilihat didalam LCD berukuran $16 \times 2$. Pada pengaturan intensitas LCD dapat diatur dari besar resistor yang terdapat pada rangkaian konfigurasi LCD, maka apabila nilai resistor di perbesar LCD akan semakin redup dan pada akhirnya mati. Kemudian pada komunikasi serial, penginialisasian baudrate pada mikrokontroller Atmega 328 di sesuaikan dengan baudrate komputer, yaitu sebesar 9600 bps. Sistem kerja alat berfungsi sebagaimana mestinya. Pada saat motor bekerja, sensor suhu akan mendeteksi adanya panas yang ditimbulkan oleh motor. Ketika suhu $31,74^{\circ} \mathrm{C}$ sampai dengan $75,20^{\circ} \mathrm{C}$ motor dalam keadaan aman, tetapi pada suhu diatas $80,51^{\circ} \mathrm{C}$ motor dalam keadaan overheating yang menyebabkan proteksi pada motor dan berhenti secara otomatis. Sebaliknya jika suhu di bawah $80,51^{\circ} \mathrm{C}$ motor kembali berputar. Apabila suhu pada motor melebihi dari suhu yang ditentukan, maka bisa diketahui bahwa motor tersebut dapat terbakar.

\section{REFERENSI}

[1] Arifianto, Deni. 2011. Kumpulan Rangkaian Elektronika Sederhana. Kawan Pustaka. Jakarta.

[2] Budi Yanto Husodo,2015. Perancangan Sistem Kontrol dan Sistem Motor Pompa Air Terhadap Gangguan Tegangan dan Arus Berbasis Arduino Jurnal Teknik Elektro, Universitas Mercu Buana.

[3] Cahyono, Moh. 2015. Rancang Bangun Proteksi Mesin Mobil Terhadap Panas (Over Heating)dan Peringatan terhadap Perubahan Tegangan Untuk Mencegah Kerusakan Aki. Jurnal Teknik Elektro, Universitas Lampung.

[ 4 ] Eko Rudiawan,2017. Sistem Minimum Sensor Suhu LM 35 Belajar Arduino. Semarang.

[ 5 ] Hari Santoso.2015. Panduan Praktis Arduino Untuk Pemula. Trenggalek

[6] Heri Andrianto.2008. Pemrogaman Mikrokontroller AVR AT MEGA 16, Informatika, Bandung,

[ 7 ] Kuswoyo, Didit Very.2015. Sistem Proteksi Motor Induksi 3 Fasa Dari Gangguan Tidak Seimbang dan Temperatur Lebih Menggunakan Mikrokontroller. Fakultas Teknik, Universitas Lampung Bandar Lampung.

[ 8 ] Lucky Pradigta S.R. 2011. Sistem Pengaman Motor Induksi 3 Phasa Terhadap Gangguan Unbalance Voltage dan Overload. Teknik Elektro Industri, PENS - ITS, Surabaya. 